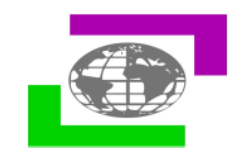

\title{
FORMULATION AND EVALUATION OF TOPICAL GEL OF ACYCLOVIR FOR TREATMENT OF VIRAL DISEASE
}

Vivek Jatwa $^{1}{ }^{*}$, M.K. Gupta ${ }^{1}$, Neetesh K Jain ${ }^{2}$, Urvashi Sharma ${ }^{2}$, Rahul Sisodiya ${ }^{2}$

${ }^{1}$ Department of Pharmacy (OCPR), Oriental University Indore-India

${ }^{2}$ University Institute of Pharmacy, Oriental University Indore-India

Article Info: Received 02 November 2019; Accepted 24 December. 2019

DOI: https://doi.org/10.32553/jbpr.v8i6.700

Corresponding Author: Vivek Jatwa

Conflict of interest statement: No conflict of interest

ABSTRACT:

Aim: Formulation \& Evaluation of Topical Gel of Acyclovir for Treatment of Viral Disease.

Material \& Methods: Acyclovir gels were formulated using different polymers like Carbopol 934, Carbopol 940, hydroxy propyl methyl cellulose and Sodium Carboxy methyl cellulose. Different concentrations of polymer were used in the formulation of gels. All the formulations were evaluated for the various parameters.

Results \& Discussion: Different formulations with use of different polymers were prepared. The amount and percentage of drug present in gel formulation using different polymers were estimated as per the procedure. The prepared gel using $1 \%$ carbopol- 934(A2) showed maximum drug content (101.72\%) compared to other formulations. The spreadability of gels was determined as per the procedure. From spreadability data is observed that the formulation with $1.0 \%$ carbopol934 showed maximum $(8 \mathrm{~cm})$, where as the formulations with $1 \%$ carbopol-940, 3\%, HPMC and Sodium CMC 3\% were showed significant spreadability. $1.0 \%$ carbopol-934 shows maximum release (74.59\%). The addition of DMSO as permeation enhancer improves the drug release from gel formulation. 1.0\% carbopol-940 also showed a similar release pattern, but the release was lesser. In case of HPMC and Sodium CMC gels the release was much lesser than carbopol gels. The addition of DMSO as permeation enhancer drug release was improved. Stability study for the best formulation was done as per the procedure. The gel was both physically and chemically stable at $4-5^{\circ} \mathrm{C}$, Room temperature and $37 \pm 5^{\circ} \mathrm{C}$.

Conclusion: From this investigation, it was concluded that formulation A2 with 1\% Carbopol-934 may be the best formulation having good in vitro release profile, stability and bioavailability. Based on the results from the study further utility of the dosage form may depend on pharmacokinetic data. Forthcoming research work of antiviral activity may contribute in the challenging area.

Keywords: Acyclovir, Topical gel, Viral Disease, Skin Disease, Formulation \& Development

\section{Introduction:}

The rationale of topical dosage form is to expediently deliver drugs across a localized area of the skin. Medications are applied to the skin in the appearance of ointments, creams, gels etc. The absorption of substances from outer surface the skin, including entrances into the blood watercourse is referred to as percutaneous absorption. It is necessary to comprehend the skin characteristics to enlarge an ideal topical dosage form (Chien YN, Lean Lackman).

Acyclovir is poorly water soluble and poor oral bioavailability, hence intravenous administration is necessary if high concentrations with fewer side effects.

Therapy for this disease is based on the application of anti-viral agents to inhibit virus growth. Topical semi-solid preparations are designed to produce local activity. Creams, gels, ointments and pastes are some of the topical semi-solids in use for many decades. These are evolved with little understanding or absorption mechanism.

Acyclovir appears to be more active anti-viral agent and is usually well tolerated. It works by stopping the spread of the HSV in the body. Non-availability of Acyclovir gels in the market is one of the reasons 
for the study. So the aim of project work is to develop gel formulation containing Acyclovir.

\section{MATERIAL \& METHODS}

\section{Formulation of Gels}

Acyclovir gels were formulated using different polymers like Carbopol 934, Carbopol 940, hydroxy propyl methyl cellulose and Sodium Carboxy methyl cellulose. Different concentrations of polymer were used in the formulation of gels. The concentrations chose varied with the polymer used. After initial trials, the concentrations that gave products of good consistency were selected for the formulation. The concentration of drug taken in all the formulation remained constant.

Table 1: Formulations with varying Carbopol-934 concentrations

\begin{tabular}{lllll}
\hline S. & Ingredients & \multicolumn{4}{l}{ Formula for $\mathbf{1 0 0}$ gms. } \\
\cline { 3 - 5 } No. & & $\mathbf{A 1}$ & $\mathbf{A 2}$ & $\mathbf{A 3}$ \\
\hline & Acyclovir & 1 & 1 & 1 \\
\hline & Carbopol-934 & 1 & 1.5 & 2.0 \\
\hline Triethanolamine & 0.5 & 0.5 & 0.5 \\
\hline & Purified water & 97.5 & 97 & 96.5 \\
\hline Methyl paraben & 0.003 & 0.003 & 0.003 \\
\hline
\end{tabular}

\section{Procedure}

1. Accurately weighed quantity of Acyclovir was dispersed in purified water with constant stirring and the drug solution was heated to $50^{\circ} \mathrm{C}$.

2. Methyl paraben was added as a preservative.

3. The carbopol-934 was added to the solution under stirring while temperature was maintained at $50^{\circ} \mathrm{C}$.

4. The dispersion of gelling agent was neutralized by addition of triethanolamine

Solution to attain the neutral pH. Stirred slowly till a clear gel was obtained (Harry G. Brittain).

Table 2: Formulations with varying Carbopol-940 concentrations

\begin{tabular}{lllll}
\hline S. & Ingredients & \multicolumn{3}{l}{ Formula for $\mathbf{1 0 0}$ gms. } \\
\cline { 3 - 5 } No. & & B1 & B2 & B3 \\
\hline & Acyclovir & 1 & 1 & 1 \\
\hline & Carbopol-940 & 1 & 1.5 & 2.0 \\
\hline & Triethanolamine & 0.5 & 0.5 & 0.5 \\
\hline & Purified water & 97.5 & 97 & 96.5 \\
\hline & Methyl paraben & 0.003 & 0.003 & 0.003 \\
\hline
\end{tabular}

\section{Procedure}

1. Accurately weighed quantity of Acyclovir was dispersed in purified water with constant stirring and the drug solution was heated to $50^{\circ} \mathrm{C}$.

2. Methyl paraben was added as a preservative.

3. The carbopol-940 was added to the solution under stirring while temperature was maintained at $50^{\circ} \mathrm{C}$

4. The dispersion of gelling agent was neutralized by addition of triethanolamine solution to attain the neutral $\mathrm{pH}$. Stirred slowly till a clear gel was obtained (Harry G. Brittain).

Table 3: Formulations with varying Hydroxy propyl methyl cellulose Concentrations

\begin{tabular}{lllll}
\hline S. & Ingredients & \multicolumn{3}{l}{ Formula for $\mathbf{1 0 0}$ gms. } \\
\cline { 2 - 5 } No. & & C1 & C2 & C3 \\
\hline \multicolumn{2}{l}{ Acyclovir } & 1 & 1 & 1 \\
\hline $\begin{array}{l}\text { Hydroxy propyl } \\
\text { methyl cellulose }\end{array}$ & 2 & 2.5 & 3.0 \\
\hline \multicolumn{2}{l}{ Purified water } & 97 & 96.5 & 96 \\
\hline & Methyl paraben & 0.003 & 0.003 & 0.003 \\
\hline
\end{tabular}

\section{Procedure}

1. Accurately weighed quantity of Acyclovir was dispersed in purified water with constant stirring and the drug solution was heated to $50^{\circ} \mathrm{C}$.

2. The solution was maintained at $50^{\circ} \mathrm{C}, \mathrm{HPMC}$ was gradually added to the

Solution under stirring until a thick viscous gel was formed.

3. Methyl paraben was added finally to the preparation as a preservative.

4. Formulation was allowed to settle down to room temperature (Harry G. Brittain).

Table 4: Formulations with varying Sodium carboxy methyl cellulose concentrations

\begin{tabular}{lllll}
\hline S. & Ingredients & \multicolumn{3}{l}{ Formula for 100 gms. } \\
\cline { 3 - 5 } No. & & D1 & D2 & D3 \\
\hline & Acyclovir & 1 & 1 & 1 \\
\hline & $\begin{array}{l}\text { Sodium } \\
\text { carboxy } \\
\text { methyl } \\
\text { cellulose }\end{array}$ & 2 & 2.5 & 3.0 \\
\hline $\begin{array}{l}\text { Purified } \\
\text { water }\end{array}$ & 97 & 96.5 & 96 \\
\hline $\begin{array}{l}\text { Methyl } \\
\text { paraben }\end{array}$ & 0.003 & 0.003 & 0.003 \\
\hline
\end{tabular}




\section{Procedure}

1. Accurately weighed quantity of Acyclovir was dispersed in purified water with Constant stirring.

2. Sodium Carboxy methyl cellulose was added under stirring to the above solution.

3. Methyl paraben was added to the dispersion under stirring as a preservative.

4. The dispersion was allowed to stand for complete hydration of Sodium CMC. Finally the weight was adjusted to $100 \mathrm{gm}$ by adding purified water (Harry G. Brittain).

\section{Evaluation of Gels}

The prepared gels were proposed to be evaluated for Drug content, pH, Viscosity, Extrudability, Spreadability, In-vitro release characteristic and the selected gel formulation subjected for Stability and In-vivo study by using Albino Rabbits (Harry G. Brittain).

\section{Standard curve of Acyclovir}

$100 \mathrm{mg}$ of accurately weighed Acyclovir was dissolved in little amount of $0.1 \mathrm{M}$ hydrochloric acid and made up to required volume $100 \mathrm{ml}$ with $0.1 \mathrm{M}$ hydrochloric acid41. So that each $\mathrm{ml}$ of stock solution required concentration of $5,10,15,20,25$, 30,35 and $40 \mu \mathrm{g} / \mathrm{ml}$ was made up with $0.1 \mathrm{M}$ hydrochloric acid. The absorbance of the dilute sample was measured spectrophotometrically at $255 \mathrm{~nm}$ using $0.1 \mathrm{M}$ hydrochloric acid in UVspectrophotometer42. The standard plot was made with concentration $(\mu \mathrm{g} / \mathrm{ml})$ on $\mathrm{X}$ axis and Absorbance on $\mathrm{Y}$ axis (Harry $\mathrm{G}$. Brittain).

Table 5: Standard curve of Acyclovir

\begin{tabular}{lll}
\hline $\begin{array}{l}\text { S } \\
\text { No. }\end{array}$ & $\begin{array}{l}\text { Concentration } \\
(\boldsymbol{\mu g} / \mathbf{m l})\end{array}$ & $\begin{array}{l}\text { Absorbance at } \\
\mathbf{2 5 5 n \mathbf { n m }}\end{array}$ \\
\hline 5 & 0.377 \\
\hline 10 & 0.531 \\
\hline 15 & 0.634 \\
\hline 20 & 0.861 \\
\hline 25 & 0.936 \\
\hline 30 & 1.23 \\
\hline 35 & 1.58 \\
\hline 40 & 1.72 \\
\hline 50 & 1.89 \\
\hline
\end{tabular}

Estimation of Drug content

$1 \mathrm{gm}$ of Acyclovir gel was dissolved in sufficient quantity of $0.1 \mathrm{M}$ hydrochloric acid to get the clear solution, volume was made up to $100 \mathrm{ml}$ with $0.1 \mathrm{M}$ hydrochloric acid. $1 \mathrm{ml}$ of the solution was diluted to $10 \mathrm{ml}$ with $0.1 \mathrm{M}$ hydrochloric acid solution. Absorbance was measured at $255 \mathrm{~nm}$ using UV spectrophotometer. The amount of Acyclovir was determined from the standard calibration curve and the percentage drug content in different formulations was calculated (Herbert A. et al).

\section{pH Measurements}

$\mathrm{pH}$ measurements of the gel were carried out using a digital $\mathrm{pH}$ meter by dipping the glass electrode completely into the gel system so as to cover the electrode (Herbert A. et al).

\section{Determination of viscosity}

Viscosities of the gels were determined by using Brookfield Viscometer (model- RVTP).Spindle type, RV-7 at $20 \mathrm{rpm}$. 100gm of the gel was taken in a beaker and the spindle was dipped in it and rotated for about 5 minutes and then reading was taken (Herbert A. et al).

\section{Extrudability}

It is useful empirical test to measure the force required to extrude the material from the tube. The formulations were filled in a collapsible metal tubes with a nasal tip of $5 \mathrm{~mm}$ opening tube extrudability was then determined by measuring the amount of gel, extruded the tip when a pressure was applied on tube gel (Herbert A. et al).

\section{Determination of spreadability}

One of the criteria for a gel meet ideal quality is that it should possess good spreadability. About 1 gm of gel formulation was weighed and kept at the center of the glass plate of standard dimensions $(10 \times 10 \mathrm{~cm})$ and another glass plate placed over it carefully, that the gel was sandwiched between the two slides. $2 \mathrm{~kg}$ weight was placed at the center of the plate (avoid sliding of the plate). The diameter of the gel in $\mathrm{cms}$, after $\mathbf{3 0}$ minutes was measured (Herbert A. et al).

\section{In vitro Drug release pattern of Acyclovir gels}

The In vitro release of Acyclovir from the gel formulation was studied by open ended cylinder method. This diffusion cell apparatus consists of a glass tube with an inner diameter of $2.5 \mathrm{~cm}$, open at the both ends. One end of the tube tied with 
Cellophane membrane, which serves as a donor compartment. $1 \mathrm{gm}$ of Acyclovir gel was taken in this compartment and placed in a beaker containing $200 \mathrm{ml}$ of $0.1 \mathrm{M}$ Hydrochloric acid stirring at moderate speed, maintain the temperature at $37 \pm 1^{\circ} \mathrm{C}$. Periodically $5 \mathrm{ml}$ of samples were withdrawn and after each withdrawal using $0.1 \mathrm{M}$ Hydrochloric acid was replaced into the diffusion medium to maintain the sink condition through out the experimentation. Then the samples were assayed by spectrophotometrically at $255 \mathrm{~nm}$ in UV-Spectrophotometer using $0.1 \mathrm{M}$ Hydrochloric acid as blank (Herbert A. et al).

\section{Stability studies of the selected gel formulation}

The assessment procedure for the stability of a pharmaceutical product lies in the capability of a formulation to retain its physical, chemical and therapeutic specifications. A general methodology for predicting the stability is accelerated stability analysis in which the materials are subjected to elevated temperatures. This does not hold good for gels, as they melt at higher temperature conditions. Thus the most commonly applied temperatures are refrigeration $\left(4-5^{\circ} \mathrm{C}\right)$, room temperature $\left(25-30^{\circ} \mathrm{C}\right)$ and $37 \pm 5^{\circ} \mathrm{C}$. Then the samples were checked at the regular intervals of 1 , 2 and 3 months. Different parameters considered for analysis are shown below (Herbert A. et al).

\section{Physical parameters}

1. Visual Appearance

2. $\mathrm{pH}$

3. Viscosity

4. Extrudability

5. Leakage

6. Nature

\section{Chemical parameters}

In this part of study, Drug content analysis of active ingredients was studied.

\section{Method}

The selected formulation was filled into aluminum collapsible tubes and stored at Room temperature, $37 \pm 5^{\circ} \mathrm{C}$ and $4-5^{\circ} \mathrm{C}$.

The gel formulation was stored for a period of three months. Samples were withdrawn at monthly intervals for a period of three months and assessed for the drug content. At the end of third month they were evaluated for physical parameter and integrity of the product.

\section{Physical evaluation of gels}

The physical parameters considered for the evaluation were Visual appearance, Nature of the product, $\mathrm{pH}$, Viscosity, Leak, Phase separation and Extrudability.

\section{Chemical evaluation}

The drug content of the formulation was estimated by withdrawing samples from different corners of the tube. The samples were mixed together and $1 \mathrm{gm}$ was taken for the assay. The estimation of drug content was carried out as per the procedure.

\section{Chemical evaluation}

The drug content of the formulation was estimated over a period of 3 months (Herbert A. et al).

\section{Skin irritation test}

The primary skin irritation test was performed on healthy albino rabbits, weighing between 2.0-3.5 $\mathrm{kg}$. The gel formulation film was prepared and used as test patches, while adhesive tape (USP) was used as control. The test was conducted on unbraided skin of the rabbits. The control and test patches were placed on the left and right dorsal surfaces of the rabbits respectively. The patches were removed after 24 hours with the help of alcohol swab and the skin was examined for erythema and edema (Jawahar et al., 2007; Chakkapan et al., 1994).

\section{RESULTS AND DISCUSSION}

\section{Formulation of Acyclovir topical gels using various gelling agents}

Gel formulations of acyclovir were prepared using different polymers namely Carbopol 934, Carbopol940, Hydroxypropyl methyl cellulose and Sodium carboxy methyl cellulose as per the procedure.

\section{Carbopol-934}

Formulations with formula A1 (1\% Carbopol-934), A2 (1.5\% Carbopol-934) and A3 (2 \% Carbopol-934) were prepared. A1 showed low consistency and $A 3$ showed very high viscosity. The gel formulation A2 (1.5\% carbopol-934) exhibited desired consistency. 
Vivek Jatwa et $a l$.

\section{Carbopol-940}

Formulations with formula B1 (1 \% Carbopol-940), B2 (1.5\% Carbopol-940) and B3 (2\% Carbopol-940) were prepared. B1 showed low consistency and B3 showed very high viscosity. The gel formulation B2 (1.5\% carbopol-940) exhibited desired consistency.

\section{Hydroxypropyl Methyl Cellulose}

Formulations with formula C1 (2.0\% HPMC), C2 (2.5\% HPMC), C3 (3.0\% HPMC) were prepared. C1 and $\mathrm{C} 2$ showed low consistency. The formulation C3 (3.0\%HPMC) exhibited desired consistency.

\section{Sodium Carboxy Methyl Cellulose}

Formulations with formula D1 (2.0\% Sodium CMC), D2 (2.5\% Sodium CMC) and D3 (3.0\% Sodium CMC) were prepared. D1 showed low consistency and D3 showed very high viscosity. The gel formulation D2 ( 2.5 \% Sodium CMC) exhibited desired consistency.

\section{Evaluation of Acyclovir gels}

All the optimized gel formulations were subjected to evaluation studies.

\section{Estimation of drug content}

The amount and percentage of drug present in gel formulation using different polymers were estimated as per the procedure. The prepared gel using $1 \%$ carbopol- 934(A2) showed maximum drug content (101.72\%) compared to other formulations. The results were shown in the Table No. 6

Table 6: Drug content estimation in various gel formulations

\begin{tabular}{|c|c|c|c|c|}
\hline S No. & Formulations & $\begin{array}{l}\text { Drug } \\
\text { (mg) }\end{array}$ & Content & $\begin{array}{l}\text { Drug } \\
\text { Content (\%) }\end{array}$ \\
\hline & $\mathrm{A} 2$ & 9.98 & & 99.8 \\
\hline & B2 & 9.48 & & 94.8 \\
\hline & $\mathrm{C} 3$ & 8.98 & & 89.8 \\
\hline & $\mathrm{D} 2$ & 9.63 & & 96.3 \\
\hline
\end{tabular}

\section{pH Measurements}

The $\mathrm{pH}$ measurements of all the gel formulations were carried out by using digital $\mathrm{pH}$ meter. The $\mathrm{pH}$ of the formulations was ranged from 6.8 to 7.2 and the results were shown in Table No.7.
Journal of Biomedical and Pharmaceutical Research

Table 7: $\mathrm{pH}$ of gel formulations

\begin{tabular}{lll}
\hline S No. & Formulations & pH \\
\hline A2 & 6.8 \\
\hline B2 & 7.2 \\
\hline C3 & 7.4 \\
\hline D2 & 7.0 \\
\hline
\end{tabular}

\section{Determination of viscosity}

The viscosity of the gels was determined using Brookfield Viscometer. The viscosity of the formulations was ranged from 36,000 to $51,000 \mathrm{cps}$ and the results were shown in Table No. 8

Table 8: Viscosity of various gel formulations

\begin{tabular}{lll}
\hline S No. & Formulations & Viscosity (cps) \\
\hline A2 & 41,000 \\
\hline B2 & 38,000 \\
\hline C3 & 39,000 \\
\hline D2 & 42,000 \\
\hline
\end{tabular}

\section{Extrudability}

The Extrudability of the gel formulations were checked as per the procedure. Extrudability of carbopol and HPMC gels was excellent than sodium $\mathrm{CMC}$ gel and the results were shown in Table No.9

Table 9: Extrudability of various gel formulations

\begin{tabular}{lll}
\hline S No. & Formulations & Extrudability \\
\hline A2 & +++ \\
\hline B2 & + \\
\hline C3 & ++ \\
\hline D2 & +++ \\
\hline
\end{tabular}

\section{Determination of Spreadability}

The spreadability of gels was determined as per the procedure. From spreadability data is observed that the formulation with $1.0 \%$ carbopol-934 showed maximum $(8 \mathrm{~cm})$, where as the formulations with $1 \%$ carbopol-940, 3\%, HPMC and Sodium CMC $3 \%$ were showed significant spreadability. The results were tabulated in Table No.10

Table 10: Spreadability of various gel formulations

\begin{tabular}{llll}
\hline $\begin{array}{l}\text { S } \\
\text { No. }\end{array}$ & Formulations & $\begin{array}{l}\text { Time } \\
\text { (minute) }\end{array}$ & $\begin{array}{l}\text { Spreadability } \\
\text { (cm) }\end{array}$ \\
\hline A2 & 15 & 9.0 \\
\hline B2 & 15 & 7.3 \\
\hline C3 & 15 & 7.5 \\
\hline D2 & 15 & 8.4 \\
\hline & & 109 | P a g e
\end{tabular}




\section{In vitro drug release of gel formulations}

In vitro drug release of gel formulations were carried out as per the procedure. The percentage release of drug from different gel formulations at the end of 8hrs was determined.

$1.0 \%$ carbopol-934 shows maximum release (74.59\%). The addition of DMSO as permeation enhancer improves the drug release from gel formulation. 1.0\% carbopol-940 also showed a similar release pattern, but the release was lesser.
In case of HPMC and Sodium CMC gels the release was much lesser than carbopol gels. The addition of DMSO as permeation enhancer drug release was improved.

Based on the drug release A2 (1.0\% carbopol-934) was the best formulation and the percentage release was found to be $74.59 \%$. So, stability and In vivo studies were carried out for A2 formulation. The percentage release of drug from different gel formulations was shown in Table No.11,12

Table 11: Drug release from Formulation A2 (Carbapol-934)

\begin{tabular}{|c|c|c|c|c|c|}
\hline S No. & Time (minute) & $\begin{array}{l}\text { Absorbance }(255 \\
\mathrm{nm})\end{array}$ & Concentration $(\mu \mathrm{g} / \mathrm{ml})$ & $\begin{array}{l}\text { Amount of drug release } \\
(\mathrm{mg})\end{array}$ & $\%$ drug release \\
\hline & 30 & 0.208 & 1.85 & 0.324 & 3.24 \\
\hline & 60 & 0.361 & 4.68 & 1.521 & 15.21 \\
\hline & 90 & 0.493 & 6.89 & 1.863 & 18.63 \\
\hline & 120 & 0.610 & 9.30 & 2.485 & 24.85 \\
\hline & 150 & 0.830 & 11.85 & 2.882 & 28.82 \\
\hline & 180 & 1.08 & 14.32 & 3.321 & 33.21 \\
\hline & 210 & 1.44 & 17.82 & 4.861 & 48.61 \\
\hline & 240 & 1.58 & 20.36 & 6.248 & 62.48 \\
\hline & 270 & 1.63 & 23.81 & 6.863 & 68.63 \\
\hline & 300 & 1.79 & 26.52 & 7.459 & 74.59 \\
\hline
\end{tabular}

Table 12: Drug release from Formulation D2 (2.5\% Sodium carboxy methyl cellulose)

\begin{tabular}{|c|c|c|c|c|c|}
\hline S No. & Time (minute) & $\begin{array}{l}\text { Absorbance }(255 \\
\mathrm{nm})\end{array}$ & Concentration $(\mu \mathrm{g} / \mathrm{ml})$ & $\begin{array}{l}\text { Amount of drug release } \\
(\mathrm{mg})\end{array}$ & $\%$ drug release \\
\hline & 30 & 0.228 & 1.10 & 0.278 & 2.78 \\
\hline & 60 & 0.323 & 4.46 & 1.142 & 11.42 \\
\hline & 90 & 0.442 & 5.67 & 1.762 & 17.62 \\
\hline & 120 & 0.535 & 8.41 & 2.661 & 26.61 \\
\hline & 150 & 0.727 & 11.52 & 2.784 & 27.84 \\
\hline & 180 & 1.09 & 13.77 & 3.883 & 38.83 \\
\hline & 210 & 1.32 & 16.48 & 4.992 & 49.92 \\
\hline & 240 & 1.44 & 19.78 & 6.374 & 63.74 \\
\hline & 270 & 1.64 & 22.52 & 6.692 & 66.92 \\
\hline & 300 & 1.76 & 27.39 & 7.214 & 72.14 \\
\hline
\end{tabular}

Stability studies for the formulation A2 (1.0\% carbopol-934)

Stability study for the best formulation was done as per the procedure. The gel was both physically and chemically stable at $4-5^{\circ} \mathrm{C}$, Room temperature and $37 \pm 5^{\circ} \mathrm{C}$. The results were tabulated in Table No. 13 \& Table No.14.

Table No.13: Physical evaluation of Formulation A2 (Carbapol-934)

\begin{tabular}{|c|c|c|c|c|}
\hline S No. & Parameters & Room Temperature & $37 \pm 5^{\circ} \mathrm{C}$ & $4-5^{0} \mathrm{C}$ \\
\hline & Visual Appearance & Transparent & Transparent & Transparent \\
\hline & $\mathrm{pH}$ & 6.8 & 6.8 & 6.8 \\
\hline & Viscosity & 41,000 & 41,000 & 41,000 \\
\hline & Extrudability & +++ & +++ & +++ \\
\hline & Leakage & No leakage & No leakage & No leakage \\
\hline & Nature & Smooth & Smooth & Smooth \\
\hline
\end{tabular}


Table 14: Drug content of Formulation A2 (Carbapol-934)

\begin{tabular}{llllll}
\hline S No. & Storage Conditions & \multicolumn{2}{l}{ Withdrawal period (Time in Month) } & & Two \\
\cline { 3 - 6 } & & Zero & One & 98.23 & Three \\
\hline & Room Temperature & 102.78 & 99.87 & 98.12 & 100.24 \\
\hline $4-5^{\circ} \mathrm{C}$ & 102.78 & 101.25 & 100.46 & 99.73 \\
\hline $37 \pm 5^{\circ} \mathrm{C}$ & 102.78 & 101.47 & 100.58 & \\
\hline
\end{tabular}

\section{Skin irritation test}

Skin irritation test was carried out as per the procedure, there was no erythema and edema and any kind of reaction. Thus the gel was found to be safer for topical use.

\section{CONCLUSION}

The present work describes a study on "Formulation and Evaluation studies of Acyclovir topical gels for Antiviral activity" Acyclovir is a broad spectrum antiviral agent against Herpes Simplex Virus and Varicella Zoster Virus, which is specific to viral-infected cells with low toxicity and which is less toxic than earlier generation of antiviral agents and as such represents a major therapeutic advance. This drug was selected for the study because it has good percutaneous absorption and appears to be more active as antiviral activity and is well tolerated. The polymers namely Carbopol-934, Carbopol-940, Hydroxypropyl methyl cellulose and Sodium carboxy methyl cellulose were used for formulation of gels and studied for their drug release from the gel formulations. It is evidence from the IR spectrum that all the polymers used in the gel formulations were compatible with the drug Acyclovir.

Different formulations of Acyclovir were prepared by using Carbopol-934, Carbopol 940, Hydroxypropyl methyl cellulose and Sodium carboxy methyl cellulose in varying proportions. Carbopol gels were transparent, non-greasy and smooth on application. Sodium CMC and HPMC gels were opaque, non-greasy and sticking on application.

The gel was prepared using 1\%Carbopol-934 has maximum drug content (101.72\%) than the others.

The $\mathrm{pH}$ of the formulations ranged from 6.8 to 7.2 and viscosity is from 36,000 to $51,000 \mathrm{cps}$.

Extrudability of carbopol and HPMC gels were excellent than the Sodium CMC gel. The spreadability data shown that the formulation with $1 \%$ Carbopol- 934 has the highest value $(8 \mathrm{~cm})$, where as the others have significant values.

In vitro release studies of the formulations were carried out across the cellophane membrane using a diffusion cell. The release was highest for the formulation A2 (1\%Carbopol-934) and on the addition of DMSO as a permeation enhancer the drug release was improved.

The formulation B2, C3 and D2 also have significant percentage release and on addition of DMSO as a permeation enhancer the drug release from gel formulation was improved. Hence based on the above results, out of 13 formulations $A 2$ was chosen as the best formulation.

Stability studies were carried out by placing the gels in collapsible tube at $4-5^{\circ} \mathrm{C}$, Room temperature and $37 \pm 5^{\circ} \mathrm{C}$ for 3 months and also analyzed for various physical and chemical parameters. The result indicates that the prepared gel was both stable physically and chemically at all storage conditions.

From the skin irritation test it was observed that the formulation $A 2$ was found to be safer for topical use. In vivo studies were carried out by collecting blood samples from albino rabbits at regular intervals. The plasma drug concentration and pharmacokinetic parameters were determined. From the above data it was observed that the bioavailability of the drug in Test was higher than Standard.

From this investigation, it was concluded that formulation A2 with 1\% Carbopol-934 may be the best formulation having good in vitro release profile, stability and bioavailability. Based on the results from the study further utility of the dosage form may depend on pharmacokinetic data. Forthcoming research work of antiviral activity may contribute in the challenging area. 


\section{REFERENCES}

1. Novel drug delivery systems by Chien YN, Volume 50- Mercel Dekker Series $2^{\text {nd }}$ Edition, P. No. 301319

2. The theory and practice of Industrial pharmacy by Leon Lackman, Herbert A. Liberman, Third Edition, P.No. 535-536

3. Profiles of Drug substance, Excipients' and related methodology, Volume-30, Edited by Harry G. Brittain, ELSEVIER Company, P.No. 3-20.
4. Herbert A., Liberman, Martin M, Rieger and Gilbert $S$ Banker. "Pharmaceutical Dosage forms: Disperse systems" Vol. 2. P.No. 506

5. Jawahar N, Anoop K.R, Ajish Prasad, Sarfaraz M.D., Gopal Rao M. Nad Jayaprakash S., THE INDIAN PHARMACIST- JUNE, 2007,68

6. Chakkapan S., Gandhi K., Thomas S., Katkam R.R. AND Shrivastava R., Indian Journal of Pharmaceutical Sciences, 1994, 56, 4. 